\title{
Impact of COVID-19 on the tourism sector in Bulgaria: state, measures to deal with the effects of pandemic
}

\author{
Violetka Zheleva $^{1 *}$, and Emil Mutafov ${ }^{1}$ \\ ${ }^{1}$ Department of Regional Development, Faculty of Economics, Trakia University, 6000 Stara Zagora, \\ Bulgaria
}

\begin{abstract}
Nowadays the tourism sector is facing challenges from different type. The physical limitations in travel, overnight stays and public health affected all forms of tourism. Since the outbreak of the COVID-19 pandemic, industries worldwide have been in a state of stagnation, collapse and insecurity which can be seen mostly in tourism sector. According to global expectations physical and mental health care are top priority, so forms of alternative tourism will be the focus of the tourism sector in near future. Current research is relying on hypothesis that alternative forms of tourism are more preferable than the mass tourism, since it is less widespread and consumers would find this form safer from a health point of view. Results will provide detailed overview of tourism sector in Bulgaria and its distribution.
\end{abstract}

\section{Introduction}

In the 20th century the tourism sector faces challenges that have not yet manifested itself even in times of economic turmoil. Physical restrictions in travel and accommodation have affected all forms of tourism. Since the outbreak of the COVID-19 pandemic, industries worldwide have been put in conditions of stagnation, collapse and uncertainty. This situation is also clearly expressed in the tourism sector. As an industry based on human mobility and close interaction, tourism and hospitality are considered to be one of the main factors for the spread of the virus. A Report of the European Parliament [1] argues that citizens' health is a top priority. Unfortunately, given the current circumstances of a global COVID-19 pandemic over the past year, it is important to pay more attention precisely to health security. The research hypothesis is that the current environment offers increased interest in alternative forms of tourism, as they are a lower mass and as a result consumers would consider that they are safer from a health point of view. There are indications that there is an interest not so much in mass activities, but rather individual events. During the period of a global pandemic of the COVID-19 virus, there is an increased demand for specialized types of tourism, and the main priority for tourists remain factors such as security and tranquility, which are leading in the choice of destination. According to expectations - health care - physical and mental, as well as rediscovery of activities taking

* Corresponding author: violetka.zheleva@trakia-uni.bg 
place in nature should also be a priority, therefore forms of alternative tourism will be a focus in the tourism sector in the coming years. Mass tourism is already losing its top spot.

\section{Impact of COVID-19 on the tourism sector in Bulgaria}

Following the introduction in $96 \%$ of countries around the world of a state of emergency, restrictions and bans [2] on travel, holding organized events, including tourist trips, increased the sense of risk during travel and a number of hotel reservations were cancelled. Despite the fact that the Ministry of Tourism of the Republic of Bulgaria [3] declared the country a "tourist destination with a seal of safety and hygiene (Safe Travels Stamp) by the World Travel and Tourism Council, an outflow of tourists was registered, which led to striking consequences for the industry. As a follow-up to the current situation, it can be argued that tourism can be a good tool for local development but should not be the only one. An uncertain future faces the resilience of most of the travel companies and destinations, especially those where cases of the disease have been recorded.

A study done as early as 2009 talked about "a change in values in the public and tourist area". It is there that the trends in the tourist market are described, which to date are already a fact [4].

Much of the tourism-related research in the time of a global pandemic is aimed at predicting changes in tourist behavior and the preferences of tourists [5-8]. The changes that have taken place since the introduction of the epidemic environment allow for the transformation of almost all sectors of the economy, including the tourism sector. This will have a long-term impact on both demand and tourism supply.

Against the background of a rapidly changing environment, new and new trends are emerging. Nationally, the data outline a new direction, which shows that the population's journeys are becoming less and less, a large part of which are mainly concentrated in the interior of the country. According to international authors, the demand for tourist products and services will increase, but will be of a different focus, namely "natural, adventurous, entertainment, rural and spiritual odyssey tourism" [9]. Tourists turn to alternative forms of tourism, which are less popular and visited by not many people in places associated with more open spaces. This stimulates the development of local tourist brands, which successfully bring certain destinations to the forefront of the tourist map and market. Pandemic restrictions require rapid adaptation to the novelties that are vital in this case.

Tourism in Bulgaria has been resilient in recent years (2016-2019). The increase in accommodation and an increase in the nights spent by both Bulgarian and foreign citizens.

To determine the state of the tourism sector in the country, data are analyzed, representing the number of nights spent and the activity of accommodation for the period 2016-2020.

The information graphically submitted is systematized on a database by the NSI [10], in Table 1 and Fig. 1 respectively. They show that the number of nights spent between 2015 and 2020 has increased sustainably and there has been a sharp decline in the pandemic situation on the same indicator. Accordingly, by $55.92 \%$ decreased the realized nights in the accommodation in the country in 2020 compared to 2019, and in the National Resorts $86.88 \%$ for the same years. This shows reduced consumption of tourist activity, in particular the nights spent in these accommodation areas provided by the National Resort Complexes in particular and generally for the country as a whole.

Table 1. Activity of national resort complexes and total for the country for the period 2015-2020 [10]

\begin{tabular}{|c|c|c|}
\hline & $\begin{array}{c}\text { Realized nights in the } \\
\text { National Complexes - } \\
\text { number }\end{array}$ & $\begin{array}{c}\text { Realized nights in } \\
\text { accommodation - total for } \\
\text { the country - number }\end{array}$ \\
\hline
\end{tabular}




\begin{tabular}{|l|l|l|}
\hline 2015 & 10108483 & 21397816 \\
\hline 2016 & 12186702 & 25185996 \\
\hline 2017 & 12383543 & 26054096 \\
\hline 2018 & 12726324 & 26845013 \\
\hline 2019 & 12345982 & 27154791 \\
\hline 2020 & 1620391 & 11968483 \\
\hline
\end{tabular}

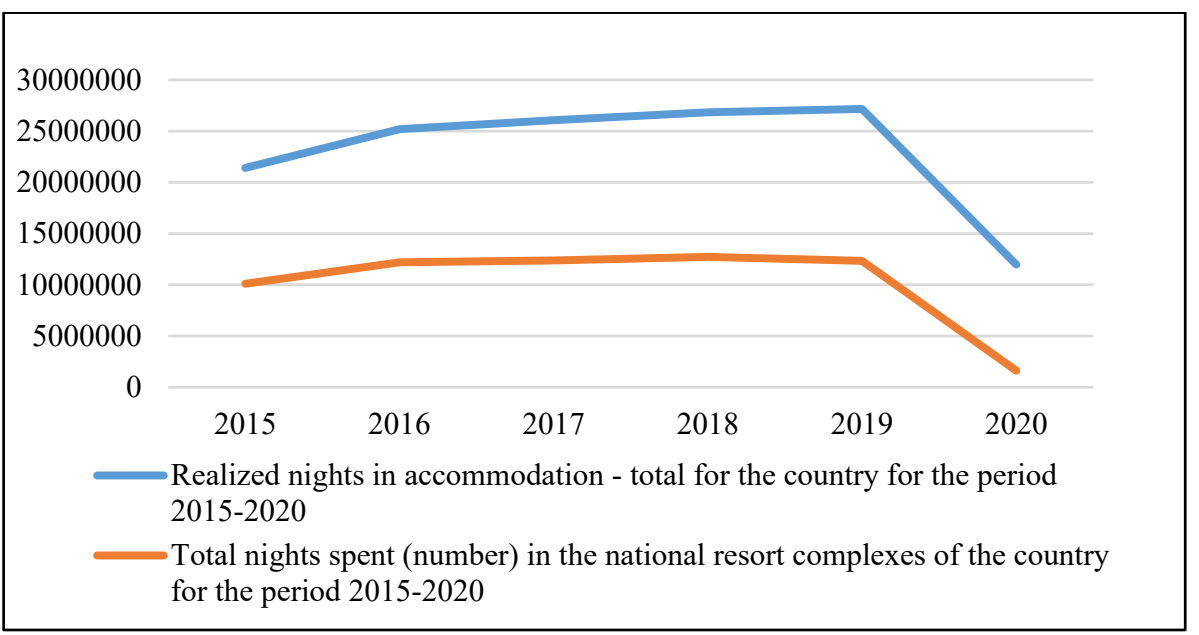

Fig. 1. Comparison between realized nights in the accommodation in the country in total and in the National Resort Complexes for the period 2015-2020. [10]

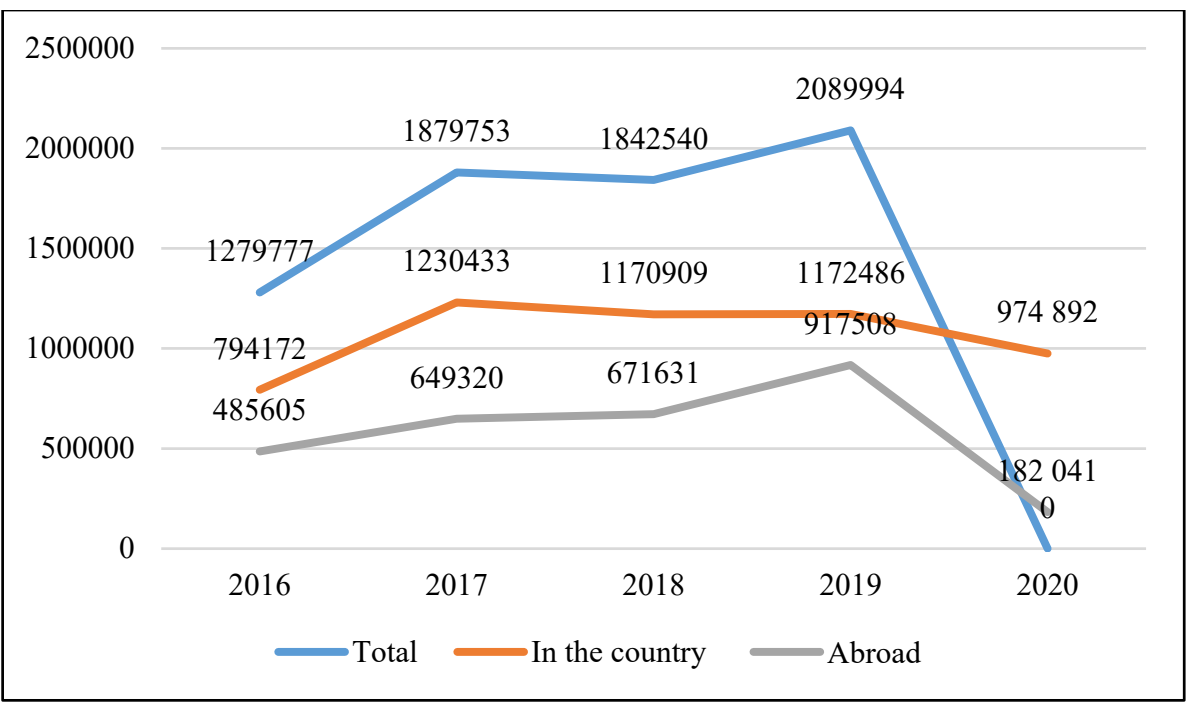

Fig. 2. Cost of tourist trips of persons 15 years and older for the period 2016 - 2020 [10] 


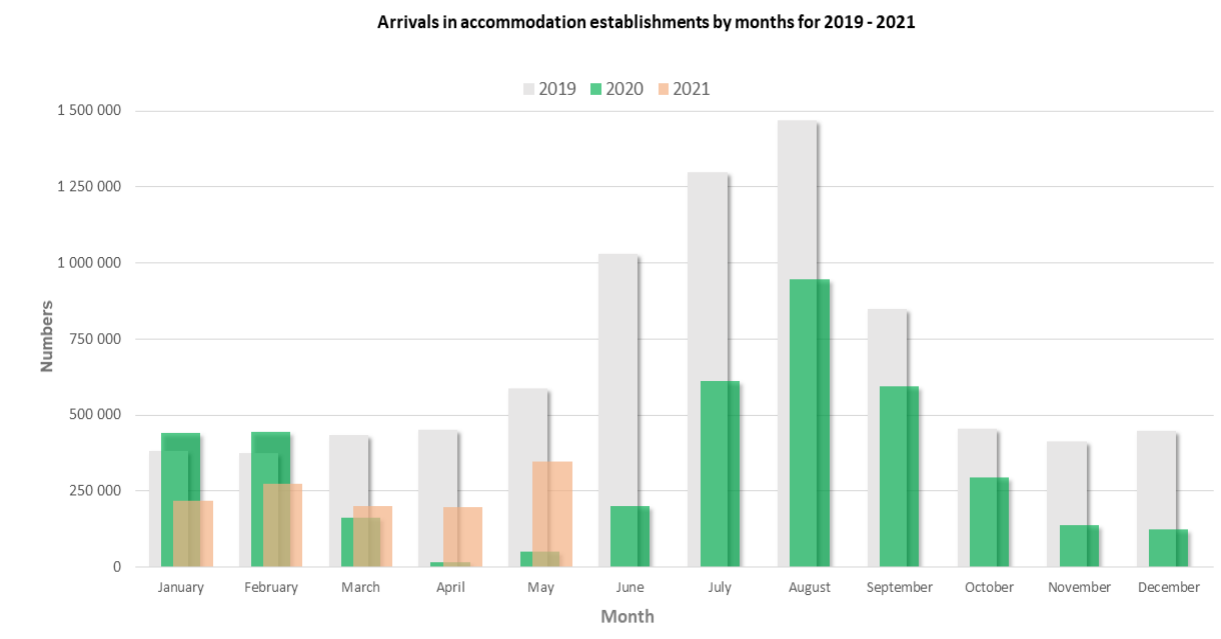

Notes:
1.Data are for accommodation establishments in use for the respective period.
2. More statistic: htrtps://infostat nsibg

Fig. 3. Stayed overnight in accommodation by month in 2019 and 2020 [10]

According to the data presented by the NSI [10] there was a sustained decrease in the realized overnight stays in accommodation in June $202080.6 \%$ compared to the same month of 2019 and reached 199.5 thousand. There was a breakdown in both foreign nationals - by $94.5 \%$ and in Bulgarian - by $59.5 \%$. The Bulgarian citizens who spent the night in the accommodation in June 2020 were 165.2 thousand. and have achieved an average of 2.3 nights. Foreign nationals are 34.3 thousand. and realized an average of 3.3 nights, $70.1 \%$ of them spent the night in hotels with 4 and 5 stars. Overnight revenue in June 2020 reached 23.1 million euro. bgn, or 88.8\% less in comparison with June 2019. There was a drop in revenues from foreign citizens - by $95.7 \%$ and by Bulgarian citizens by $60.3 \%$.

Potential reasons for the decrease in the realized nights can also be searched in the current morbidity map in the country for 2020. On Fig. 13, 2013 there is a trend of rise after September 2020.

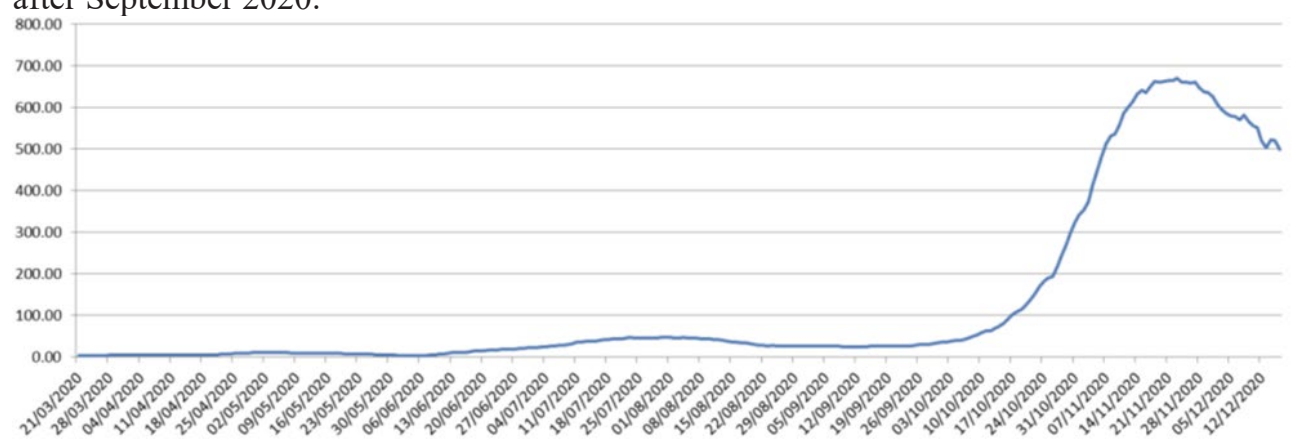

Fig. 4. 14-day covid-19 morbidity in Bulgaria, 2020 [11]

Given the real statistical results of morbidity and declining overnight stays in the period from October 2020, we can draw a conclusion about the correlation between the nights realized and the increase in morbidity.

Although upon termination of the package contract, the traveller is entitled to a full refund of all payments made for the package, this does not even lead to similar levels of 
bookings or nights spent. By comparison, according to data of the NSI [10] for December 2020, 6 times less nights spent by foreigners were recorded compared to the same period the previous year.

\section{Measures to address the effects of COVID-19}

In 2020, the first study [12] examined the impact of COVID-19 on the hospitality industry. It addressed six phases of disaster management, which also addressed the economic health crisis. These phases can also be recognized in the Bulgarian tourism industry.

In order to return the tourism industry to its former form, it is necessary to develop and implement a number of post-pandemic measures to deal with the situation. Like state intervention, it's crucial. As already mentioned, the Ministry of Tourism of the Republic of Bulgaria [3] declared the country a "tourist destination with a seal of safety and hygiene (Safe Travels Stamp) from the World Travel and Tourism Council" and took a step towards achieving one of the main goals - revitalization of the tourism sector. It is this measure that needs to regain consumer confidence by working towards improving two key aspects: health security and health requirements. Of course, this corresponds and complements the thesis that alternative forms of tourism will be brought to the fore, as they are practiced independently or by small groups of tourists seeking calm destinations and attractions, and they in turn offer successful safety and health measures, as well as any activities, creating the feeling in tourists to feel more relaxed.

A study done in 2020 [13] shows the extent to which tourists perceive a possible risk to their health during tourist trips through a pandemic of COVID-19. According to another study [9] "tourists have lost confidence in host communities in many countries, and similarly host countries have also lost confidence in tourists who need to be restored." The author argues that it takes some time to stabilize things, while paying attention to the positive and negative impact on the tourism industry.

A study [14] conducted specifically among Bulgarian users of tourist services shows that cleanliness and hygiene requirements in accommodation establishments are an extremely important factor during their travels, and they consider that it is the large hotel chains that are not reliable enough in this regard. Clearly express their position that they prefer to stay in hotels of the "family" type or guesthouses.

On 15 April 2020, the European Commission, in cooperation with the President of the European Parliament, presented a Joint European Roadmap on the gradual abolition of restrictive measures in COVID-19 outbreaks. It set out criteria and recommendations for Member States on the conditions for repealing measures and restoring the free movement of persons. Among them, special attention is paid precisely to the protection of the health of citizens, including tourism workers and tourists [15].

\section{References}

1. Report of the European Parliament 2020/2038(INI), https://www.europarl.europa.eu/doceo/document/A-9-2021-0033 EN.html

2. UNWTO Reports, Covid-19 response: $96 \%$ of global destinations impose travel restrictions, (2020), https://www.unwto.org/news/covid-19-response-travel-restrictions

3. Ministry of Tourism of the Republic of Bulgaria, https://www.tourism.government.bg/bg/kategorii/novini/bulgariya-shte-polzva-pechatza-bezopasnost-i-higiena-ot-svetovniya-suvet-za

4. M. Yaneva, Economic Alternatives, 2, 11 (2009) 
5. P. Brouder, Tour. Geograph., 22(3), 484-490 (2020)

6. F. Higgins-Desbiolles, Tour. Geograph., 22(3), 610-623 (2020)

7. S. Nepal, Tour. Geograph., 22(3), 646-650 (2020)

8. S. Wachyuni, D. Kusumaningrum, J. Education, Society and Behavioural Sci., 33(4), 67-76 (2020)

9. C. Choudhary, CORONA (Covid-19) And Tourism: More Opportunities in The Aftermath of The Lockdown, (Gambella University, Ethiopia, 2020)

10. National Statistical Institute, https://www.nsi.bg/bg/content/

11. Ministry of Health Report, https://www.mh.government.bg/media/filer_public/2020/12/18/75-01-58.pdf

12. F. Hao, Q. Xiao, K. Chon, Int. J. Hospit. Manag., 90, 102636 (2020)

13. L. Neuburger, Curr. Issues Tour., 24(7), 1003-1016 (2021)

14. N. Naumov, D. Varadzhakova, A. Naydenov, Anatolia, 32(1), 144-147, (2021)

15. Communication from the Commission COVID-19: EU, Guidance for the progressive resumption of tourism services and for health protocols in hospitality establishments, Brussels, 13.5.2020 C3251 final (2020) 